\title{
SPATIAL PERCEPTION ELEMENTS IN JAMI'E DARUSSALAM MOSQUE, CENTRAL JAKARTA
}

\author{
${ }^{1}$ Ines Dwihutari. ${ }^{2}$ Yenny Gunawan, S.T., M.A. \\ ${ }^{1}$ Student in the Bachelor's (S-1) Study Program in Architecture \\ at Parahyangan Catholic University \\ ${ }^{2}$ Senior lecturer in the Bachelor's (S-1) Study Program in Architecture \\ at Parahyangan Catholic University
}

\begin{abstract}
In the course of the development of Islam since the time of the Prophet Muhammad until now, the strategic position of the mosque is not only as a place of worship but also as the center of Islamic Introduction. As we know that establishing a mosque is a culture that has been rooted in the life of Muslim society. The founding principle of the mosque comes from the teachings contained in the Qur'an and Hadith. However, the two sources did not disclose and include the building and physical codes of the mosque. All of it is left to the people to design their own buildings and physical mosque in accordance with the conditions of the local community. The mosque in Indonesia is developed into two forms, the first being a form influenced by the local culture. The second is a form influenced by middle eastern culture. Then, a mosque with a different shape from the two previously described forms began to appear. One of the mosques is the Jami'e Darussalam, the mosque which became the object of research.

The study was conducted based on a preliminary study conducted by studying the theory of space perception put forward by Bert Bielefeld and the theory of space perception in the mosque. From the existing theory can then be formulated an indicator of the perception of space needed in a mosque. Existing indicators are then used to research buildings with a focus on the perception of space. The result of object study analysis then further be processed through the analysis table so that it can be inferred the space forming element that influence the human perception on the mosque.

From the research, it is found that the perception of space needed in a mosque is only in the prayer room of Jami'e Darussalam Mosque, but not in other spaces. This is because the character of different space-forming elements in each space.

The benefit of this research for the general public is to increase knowledge about the perception of space needed in a mosque and how the perception of space can be realized. Meanwhile, for the architects and mosque institutions, this research can add knowledge about the perception of space in a mosque and how to design the elements of space to be able to realize the perception of space.
\end{abstract}

Key Words: elements of space formation, perception of space, mosque

\section{ELEMEN PEMBENTUK PERSEPSI RUANG PADA MASJID JAMI'E DARUSSALAM, JAKARTA PUSAT}

\author{
${ }^{1}$ Ines Dwihutari. ${ }^{2}$ Yenny Gunawan, S.T., M.A. \\ ${ }^{1}$ Mahasiswa S1 Program Studi Arsitektur Universitas Katolik Parahyangan \\ ${ }^{2}$ Dosen Pembimbing S1 Program Studi Arsitektur Universitas Katolik Parahyangan
}

\begin{abstract}
Abstrak- Dalam perjalanan perkembangan Agama Islam sejak zaman Rasulullah SAW sampai saat ini posisi strategis masjid tidak saja sebagai tempat ibadah tetapi juga sebagai pusat syiar Islam. Sebagaimana kita ketahui bahwa mendirikan masjid adalah suatu budaya yang telah mengakar dalam kehidupan masyarakat umat Islam. Asas pendirian masjid bersumber dari ajaran yang terkandung dalam Al-Qur'an dan Hadits. Namun kedua sumber tersebut tidak mengungkapkan dan mencantumkan aturan-aturan bangunan dan fisik masjid. Semua itu diserahkan
\end{abstract}

${ }^{1}$ Corresponding Author: dwihutariines@gmail.com 
kepada umat untuk merancang sendiri bangunan dan fisik masjid sesuai dengan kondisi masyarakat setempat. Masjid di Indonesia berkembang menjadi dua bentuk, yang pertama adalah bentuk yang dipengaruhi oleh kebudayaan setempat. Kedua adalah bentuk yang dipengaruhi oleh kebudayaan timur tengah. Kemudian masjid dengan bentuk yang berbeda dari kedua bentuk yang telah dijelaskan sebelumnya mulai bermunculan. Salah satu dari masjid tersebut adalah Masjid Jami’e Darussalam yang menjadi objek penelitian.

Penelitian dilakukan berdasarkan studi awal yang dilakukan dengan mengkaji teori persepsi ruang yang dikemukakan oleh Bert Bielefeld dan teori persepsi ruang pada masjid. Dari teori yang ada kemudian dapat dirumuskan suatu indikator berupa persepsi ruang yang diperlukan dalam sebuah masjid. Indikator yang telah ada kemudian digunakan untuk meneliti bangunan dengan fokus kepada persepsi ruang. Hasil analisa objek studi kemudian diolah lebih lanjut melalui tabel analisa sehingga dapat disimpulkan elemen pembentuk ruang yang mempengaruhi persepsi manusia pada masjid.

Dari penelitian tersebut, didapatkan hasil bahwa persepsi ruang yang diperlukan dalam sebuah masjid hanya ada pada ruang shalat Masjid Jami'e Darussalam, namun tidak pada ruang-ruang lainnya. Hal tersebut dikarenakan karakter elemen pembentuk ruang yang berbeda-beda pada setiap ruang.

Manfaat dari penelitian ini bagi kaum umum adalah dapat menambah pengetahuan mengenai persepsi ruang yang diperlukan dalam sebuah masjid dan bagaimana persepsi ruang tersebut dapat terwujud. Sementara itu bagi para arsitek dan lembaga masjid, penelitian ini dapat menambah pengetahuan mengenai persepsi ruang dalam sebuah masjid serta bagaimana merancang elemen-elemen pembentuk ruang untuk dapat mewujudkan persepsi ruang tersebut.

Kata Kunci: elemen pembentuk ruang, persepsi ruang, masjid

\section{PENDAHULUAN}

Masyarakat Indonesia mayoritas memeluk agama Islam, dimana masjid menjadi wadah pusat peribadatan dan pusat kebudayaan masyarakat Islam di sekitarnya. Masjid memiliki peran yang sangat besar dalam membangun dan membentuk citra kepribadian dan budaya bangsa. Asas pendirian masjid bersumber dari ajaran yang terkandung dalam Al-Qur'an dan Hadits. Namun kedua sumber tersebut tidak mengungkapkan dan mencantumkan aturan-aturan bangunan dan fisik masjid. Semua itu diserahkan kepada umat untuk merancang sendiri bangunan dan fisik masjid sesuai dengan kondisi masyarakat setempat (Departemen Agama, 2008).

Masjid di Indonesia berkembang menjadi dua bentuk, yang pertama adalah bentuk yang dipengaruhi kebudayaan setempat. Pada zamannya, para walisongo mendirikan masjid dengan menyesuaikan nilai-nilai budaya masyarakat setempat yang saat itu telah menjadi kebudayaan yang sangat kuat. Mereka berusaha untuk memasukkan ajaran Islam ke dalam kesenian Jawa. Mereka tidak menerapkan bentuk dan bangunan yang ada di negeri Islam, melainkan selalu memanfaatkan potensi setempat (Departemen Agama, 2008). Kedua adalah bentuk yang dipengaruhi kebudayaan timur tengah. Saat ini hampir semua masyarakat memberikan satu persepsi yang sama terhadap karakteristik sebuah masjid. Secara umum persepsi tersebut adalah berbentuk dasar kotak, memiliki kubah, memiliki menara, memiliki bukaan lebar dengan ornamen lengkung menyerupai bawang dan sebagainya (Suharjanto, 2013). Kemudian masjid dengan bentuk yang berbeda dari kedua bentuk yang telah dijelaskan sebelumnya mulai bermunculan. Beberapa dari masjid tersebut adalah karya arsitek Ridwan Kamil dan Urbane Indonesia.

Salah satu masjid dengan bentuk yang berbeda dari bentuk masjid pada umumnya adalah objek penelitian ini yaitu Masjid Jami'e Darussalam, merupakan salah satu masjid rancangan Ridwan Kamil dan Urbane Indonesia. Alasan pemilihan objek adalah karena bentuknya yang berbeda dari kedua bentuk masjid yang sudah dijelaskan sebelumnya dan memiliki dua lantai. Lantai satu berbentuk kubus dengan fungsi sebagai ruang ibadah wanita dan ruang-ruang penunjang. Lantai dua berbentuk segitiga dengan fungsi sebagai ruang ibadah pria, serta terdapat kubus yang menonjol sebagai mihrab. Meskipun bentuknya yang sangat 
modern kontras dengan pemukiman disekitarnya, bentuk ruang ibadah pria menciptakan pengalaman ruang yang sangat unik baik dari dalam maupun dari luar
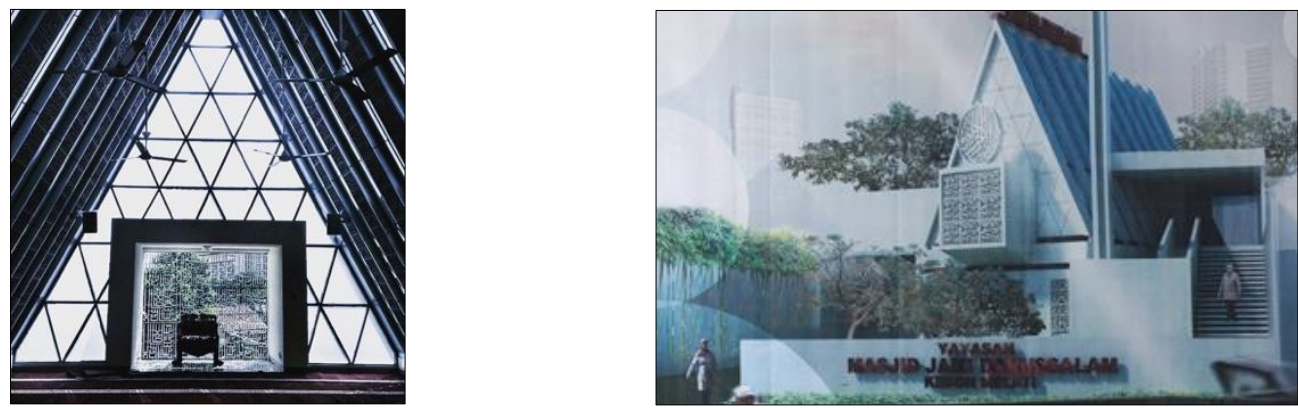

Gambar 1.1 Masjid Jami'e Darussalam, Jakarta Pusat (Sumber: www.id.pinterest.com/source/instagram.com/, 2017)

Penelitian ini fokus pada hubungan antara elemen fisik spasial Masjid Jami'e Darussalam dengan persepsi sensori pengguna. Panca indera menjadi tolak ukur bagaimana pengguna mendefinisikan hal-hal yang mereka rasakan. Pengguna diharapkan dapat mendefinisikan ruang ibadah mereka melalui persepsi sensori tersebut.

Masjid Jami'e Darussalam memiliki elemen-elemen fisik spasial yang berbeda dari perancangan masjid pada umumnya, sehingga membentuk persepsi ruang yang unik. Oleh karena itu, diperlukan adanya penelitian mengenai seperti apa persepsi ruang yang dialami pengguna Masjid Jami’e Darussalam. Maka, dari perumusan masalah tersebut dapat dibuat pertanyaan penelitian sebagai berikut :

- Persepsi ruang seperti apa yang dialami pengguna Masjid Jami’e Darussalam?

- Elemen ruang seperti apa yang menyebabkan munculnya persepsi ruang pada Masjid Jami'e Darussalam?

\section{KAJIAN TEORI}

\subsection{PERSEPSI RUANG PADA MASJID DAN ELEMEN-ELEMEN PEMBENTUKNYA}

Persepsi ruang adalah kemampuan manusia dalam memahami ruang yang dibuat untuk memenuhi kebutuhannya. Manusia secara konstan menggunakan ruang baru dalam kehidupan sehari-harinya. Sebagian besar informasi dari ruang tersebut diproses dengan sangat cepat oleh panca indra dan sistem kognitif yang kemudian mempengaruhi perilaku tanpa perlu untuk mengaktifkan sistem berpikir. Proses mempersepsi dengan cepat membuat suatu ruang terasa nyaman atau tidak nyaman, sesak atau melindungi, tanpa perlu memahami masing-masing karakteristik ruangnya (Bert Bielefeld, 2013).

Faktor-faktor yang mempengaruhi persepsi pada dasarnya dibagi menjadi dua, yaitu faktor internal dan faktor eksternal (Aly Noordien (2012). Faktor Internal adalah faktor-faktor yang terdapat dalam diri manusia yaitu fisiologis, perhatian, minat, kebutuhan yang searah, pengalaman dan ingatan, serta suasana hati (Aly Noordien (2012). Sedangkan faktor eksternal adalah karakteristik dari lingkungan dan objek-objek yang terlibat didalamnya yaitu komposisi, proporsi, dimensi, struktur, pembatas, penghubung, lapisan, transparansi, 
koreografi, cahaya, pembayangan, temperatur, kelembaban, suara, bau, material, tekstur, ornamen, warna dan furnitur Bert Bielefeld, 2013). Faktor-faktor eksternal tersebut diterima oleh panca indera dan dipengaruhi oleh faktor-faktor internal. Kemudian terbentuklah kesadaran ruang berupa visual space, audial space, tectile space, olfactual space, thermal space dan khinestetic space (Hall E, 1966). Kesadaran ruang tersebut yang menimbulkan persepsi.

Masjid merupakan sebuah bangunan yang didalamnya terdapat ruang-ruang yang memiliki persepsi berbeda-beda tergantung dari karakteristik ruangnya. Masjid memiliki asas pendirian yang bersumber dari ajaran yang terkandung dalam Al-Qur'an dan Hadits. Namun kedua sumber tersebut tidak mengungkapkan dan mencantumkan aturan-aturan bangunan dan fisik masjid. Semua itu diserahkan kepada umat untuk merancang sendiri bangunan dan fisik masjid sesuai dengan kondisi masyarakat setempat. Walaupun begitu terdapat faktor-faktor penting yang harus diperhatikan, salah satunya adalah dapat memberikan pengalaman rohaniah yang sangat berharga dan dapat menyentuh serta menimbulkan perasaan-perasaan lain, yaitu syahdu, kagum, terharu dan nyaman (Departemen Agama, 2008). Syahdu adalah hikmat, mulia dan agung. Kagum adalah takjub dan tercengang. Nyaman adalah segar, sehat, sedap, sejuk dan enak. Sedangkan terharu adalah tersentuh dan terenyuh (Kamus Besar Bahasa Indonesia).

\section{METODA PENELITIAN}

Jenis penelitian yang dilakukan berupa penelitian kualitatif deskriptif yang ditujukan untuk mendeskripsikan dan menganalisis persepsi manusia secara kelompok. Penelitian berawal dari dilakukannya studi literatur yang terkait dengan persepsi ruang dan arsitektur masjid. Teori-teori tersebut kemudian dirumuskan menjadi satu indikator yang digunakan untuk menganalisis obyek studi dalam penelitian ini, yaitu Masjid Jami'e Darussalam.

Penelitian dilakukan hanya pada ruang-ruang yang dilalui dan digunakan oleh pengguna pria. Hal tersebut dikarenakan kewajiban pria untuk beribadah di masjid, selain itu juga dikarenakan ruang ibadah pria adalah fenomena yang terdapat pada masjid ini. Berdasarkan hal tersebut, ruang-ruang yang diteliti adalah:
1. Area pintu masuk depan
2. Area prefunction
3. Area toilet dan wudhu
4. Area tangga
5. Area transisi
6. $\quad$ Ruang shalat
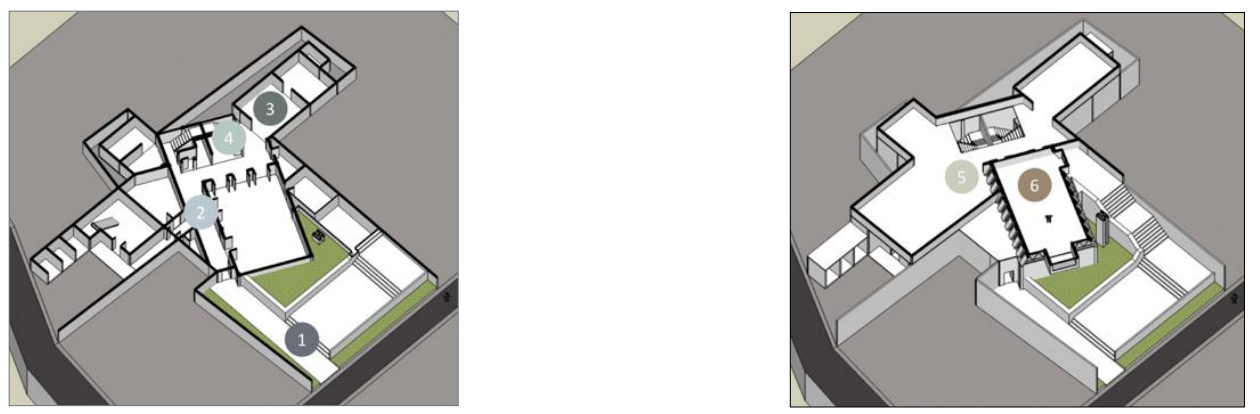

Gambar 3.1 Lantai Dasar Masjid Jami'e Darussalam

Gambar 3.2 Lantai Atas Masjid Jami'e Darussalam

Sumber data pada penelitian ini terbagi menjadi dua yaitu :

a. Data Primer 
Data primer yang pertama adalah data fisik berupa gambar kerja (denah, tampak dan potongan), tiga dimensi, serta foto-foto. Kemudian data primer yang kedua adalah data persepsi yang didapatkan melalui wawancara informal dengan menggunakan kuisioner. Kuisioner dibuat berdasarkan elemen ruang yang ada pada Masjid Jami'e Darussalam dan berdasarkan kajian teori yang telah dilakukan sebelumnya.

b. Data Sekunder

Data Sekunder merupakan data yang mendukung penelitian seperti historis dan perkembangan, data kegiatan, serta studi pustaka yang telah dilakukan.

Setelah memperoleh data hasil wawancara, data tersebut kemudian diklasifikasikan dan menghasilkan persepsi ruang yang dirasakan oleh pengguna pada setiap ruang, indra yang terlibat dan tidak terlibat, serta elemen-elemen pembentuk ruang apa saja yang mempengaruhi dalam membentuk persepsi tersebut. Selanjutnya dilakukan identifikasi terhadap elemenelemen pembentuk ruang yang terdapat pada ruang-ruang yang diteliti dan menjabarkannya melalui gambar-gambar dan penjelasan. Terakhir, dilakukan analisa terhadap hubungan antara elemen-elemen ruang yang sudah diidentifikasi dengan persepsi ruang yang terbentuk, indra yang terlibat dan elemen-elemen ruang yang mempengaruhi berdasarkan hasil wawancara. Analisa tersebut dijelaskan dan dijabarkan dalam bentuk tabel analisa.

\section{ANALISA}

\subsection{ELEMEN RUANG PADA MASJID JAMI'E DARUSSALAM}

Penelitian ini dilakukan terhadap area pintu masuk, area prefunction, ruang wudhu dan toilet, area tangga, area transisi dan ruang shalat seperti yang sudah dijelaskan sebelumnya. Ruang-ruang tersebut memeiliki elemen-elemen tersendiri. Elemen-elemen yang dimaksud adalah komposisi, proporsi, dimensi, struktur, pembatas, penghubung, lapisan, transparansi, koreografi, cahaya, pembayangan, temperatur, kelembaban, suara, bau, material, tekstur, ornamen, warna dan furnitur. Elemen-elemen tersebut akan membentuk karakteristik tersendiri pada tiap ruang.

Berdasarkan hasil identifikasi terhadap ruang-ruang pada Masjid Jami’e Darussalam, terdapat ruang-ruang yang memiliki karakteristik yang serupa dan terdapat ruang-ruang yang memiliki karakteristik yang berbeda. Ruang-ruang yang memiliki karakteristik serupa adalah area prefunction, ruang wudhu dan toilet, area tangga serta area transisi. Sedangkan ruangruang yang memiliki karakteristik yang berbeda adalah area pintu masuk dan ruang shalat.

\subsection{HUBUNGAN ELEMEN RUANG DENGAN PERSEPSI RUANG PADA MASJID JAMI'E DARUSSALAM}

Berdasarkan data hasil kuisioner, persepsi yang terbentuk pada area pintu masuk adalah syahdu, kagum, dan nyaman. Namun persepsi syahdu dan nyaman hanya dirasakan hanya oleh sedikit orang yaitu dibawah 10 orang. Sedangkan persepsi yang paling banyak dirasakan adalah kagum. Persepsi yang terbentuk pada area prefunction adalah nyaman dan kurang nyaman. Namun persepsi kurang nyaman hanya dirasakan hanya oleh sedikit orang yaitu dibawah 5 orang. Sedangkan persepsi yang paling banyak dirasakan adalah nyaman. Persepsi yang terbentuk pada ruang wudhu dan toilet adalah nyaman. Persepsi yang terbentuk pada area tangga adalah nyaman dan kurang nyaman. Namun persepsi kurang nyaman hanya dirasakan hanya oleh sedikit orang yaitu dibawah 5 orang. Sedangkan persepsi yang paling banyak dirasakan adalah nyaman. Persepsi yang terbentuk pada area transisi adalah nyaman dan kagum. Namun persepsi kagum hanya dirasakan hanya oleh sedikit orang yaitu 5 orang. Sedangkan persepsi yang paling banyak dirasakan adalah nyaman. Persepsi yang terbentuk 
pada ruang shalat adalah syahdu, kagum, nyaman dan terharu. Keempat persepsi tersebut banyak dirasakan oleh pengunjung. Namun yang paling banyak dirasakan adalah syahdu dan nyaman. Sedangkan persepsi terharu adalah yang paling sedikit dirasakan.

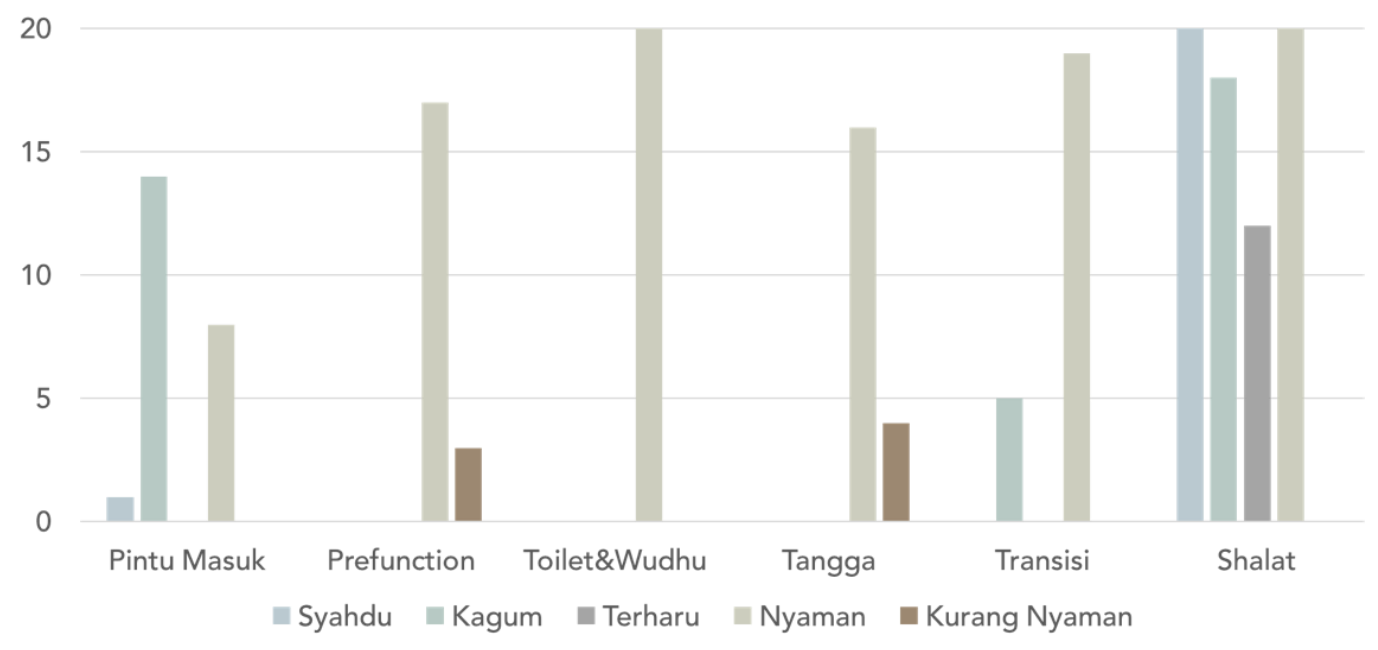

Gambar 5.1 Diagram Persepsi Ruang pada Masjid Jami'e Darussalam

\subsubsection{AREA PINTU MASUK UTAMA}

Pada area pintu masuk utama, persepsi yang muncul adalah syahdu, kagum dan nyaman. Namun persepsi yang paling dominan dirasakan adalah kagum. Berdasarkan hasil data kuisioner, persepsi tersebut terbentuk dengan melibatkan kesadaran visual, tectile, thermal dan khinestetic, namun yang paling dominan adalah visual, tanpa melibatkan kesadaran audial dan olfactual.

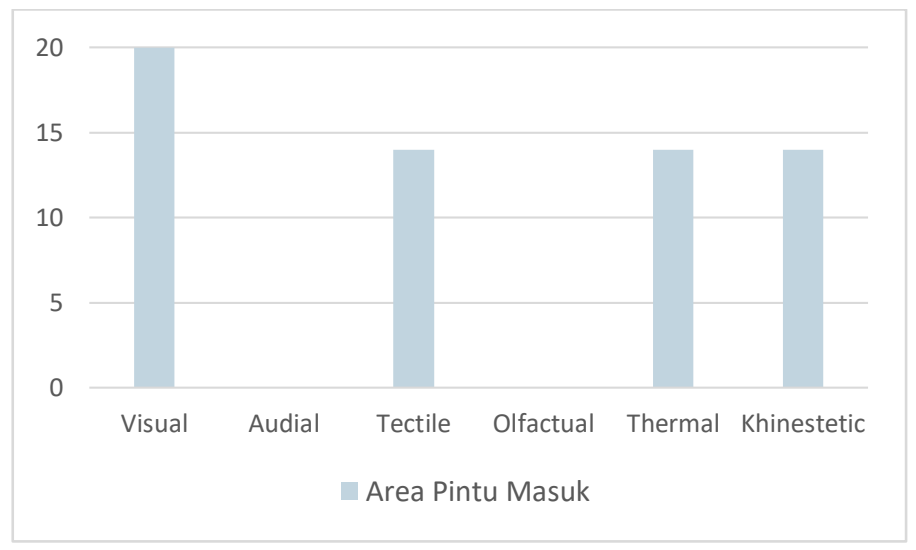

Gambar 5.2 Kesadaran Ruang yang Terlibat Dalam Pembentukan Persepsi Area Pintu Masuk

Berdasarkan hasil data kuisioner, elemen ruang yang membentuk persepsi tersebut adalah komposisi, proporsi, dimensi, struktur, penghubung, pembatas, lapisan, transparansi, koreografi, cahaya, pembayangan, temperatur, material, tekstur, ornamen, warna dan furnitur. Elemen ruang yang paling mempengaruhi adalah komposisi, proporsi, dimensi. Kemudian yang paling tidak mempengaruhi adalah suara dan bau. 


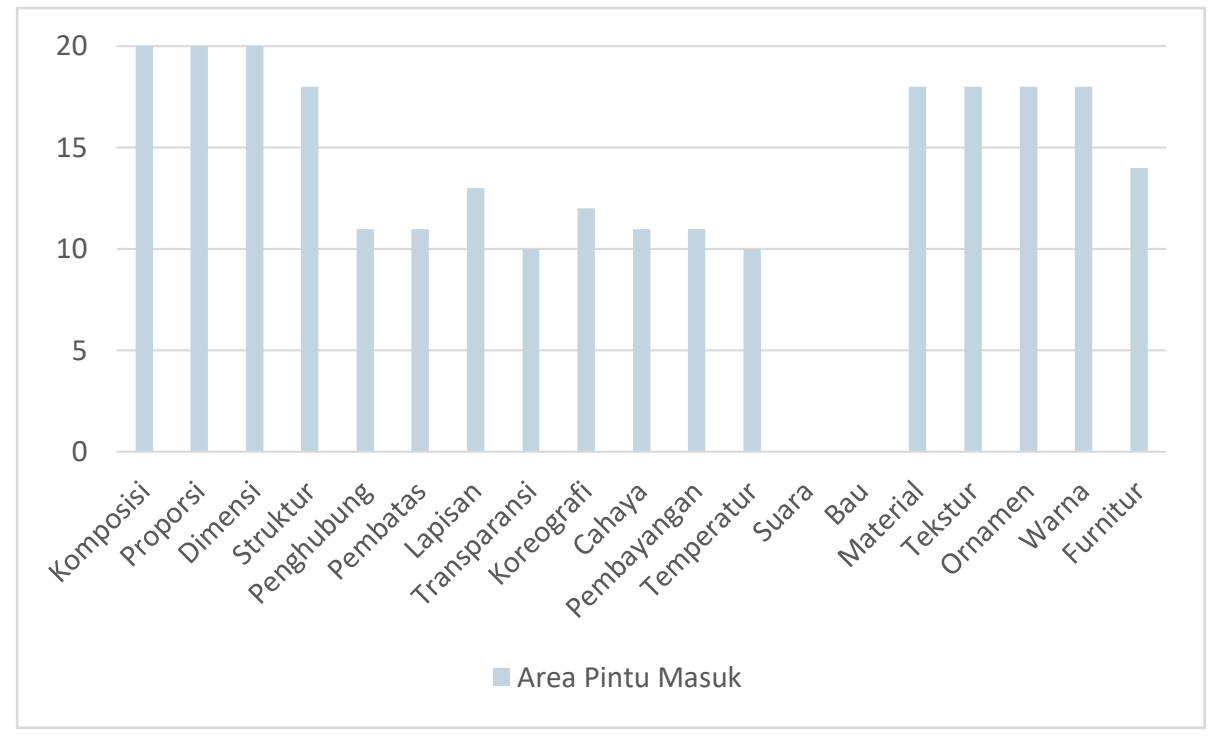

Gambar 5.3 Elemen Ruang yang Membentuk Persepsi Area Pintu Masuk

\subsubsection{AREA PREFUNCTION}

Pada area prefunction, persepsi yang muncul adalah nyaman dan kurang nyaman. Namun persepsi yang paling dominan dirasakan adalah nyaman. Berdasarkan hasil data kuisioner, persepsi tersebut terbentuk dengan melibatkan kesadaran visual, tectile, thermal dan khinestetic, tanpa melibatkan kesadaran audial dan olfactual.

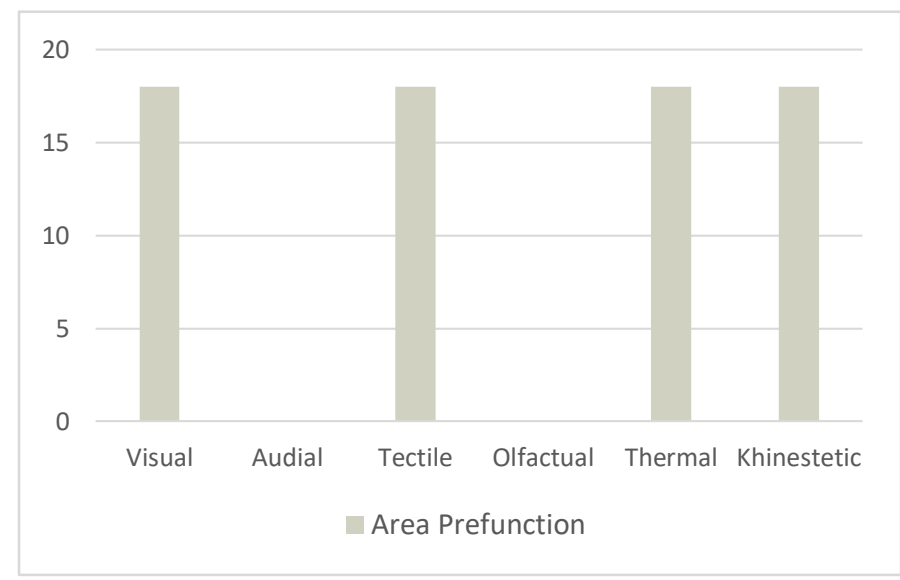

Gambar 5.4 Kesadaran Ruang yang Terlibat Dalam Pembentukan Persepsi Area Prefunction

Berdasarkan hasil data kuisioner, elemen ruang yang membentuk persepsi tersebut adalah komposisi, proporsi, dimensi, penghubung, pembatas, koreografi, cahaya, pembayangan, temperatur, material, tekstur, ornamen, dan warna. Elemen ruang yang paling memengaruhi adalah temperatur, material, tekstur, ornamen, dan warna. Kemudian yang paling tidak mempengaruhi adalah struktur, lapisan, transparansi, suara, bau, dan furnitur. 


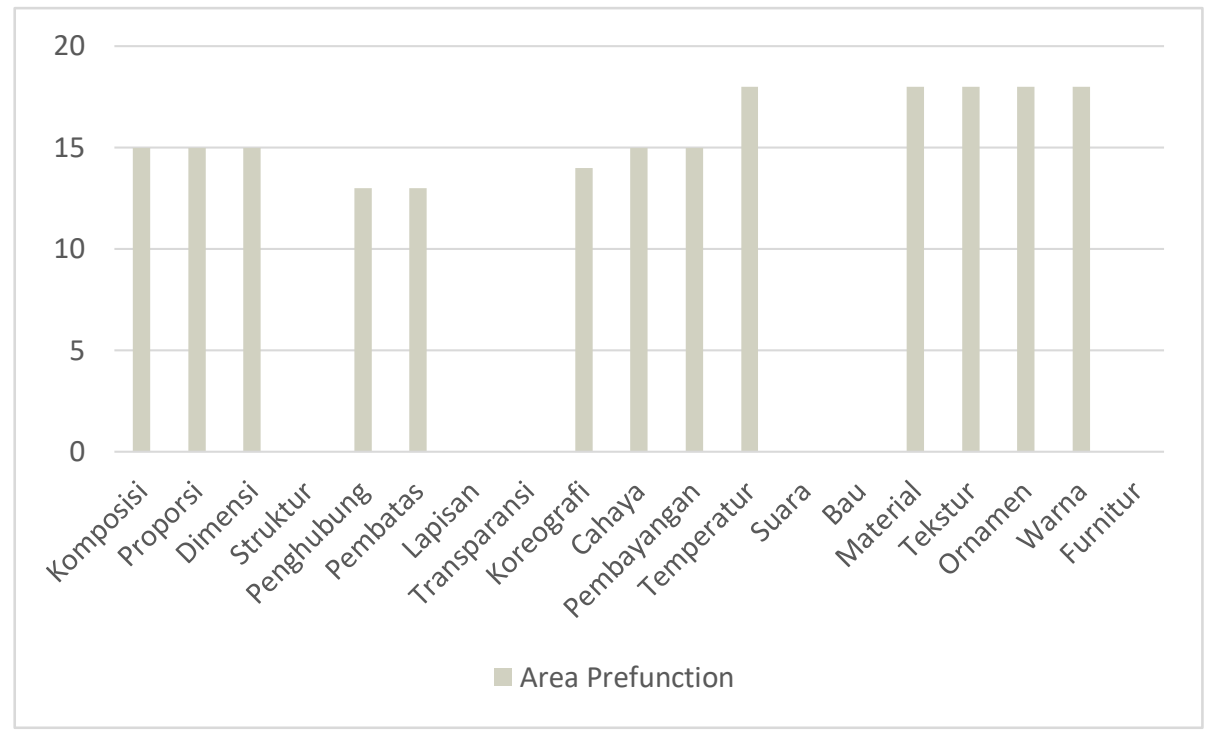

Gambar 5.5 Elemen Ruang yang Membentuk Persepsi Area Prefunction

\subsubsection{RUANG WUDHU DAN TOILET}

Pada ruang wudhu dan toilet, persepsi yang muncul adalah nyaman. Berdasarkan hasil data kuisioner, persepsi tersebut terbentuk dengan melibatkan kesadaran visual, tectile, thermal dan khinestetic, tanpa melibatkan kesadaran audial dan olfactual.

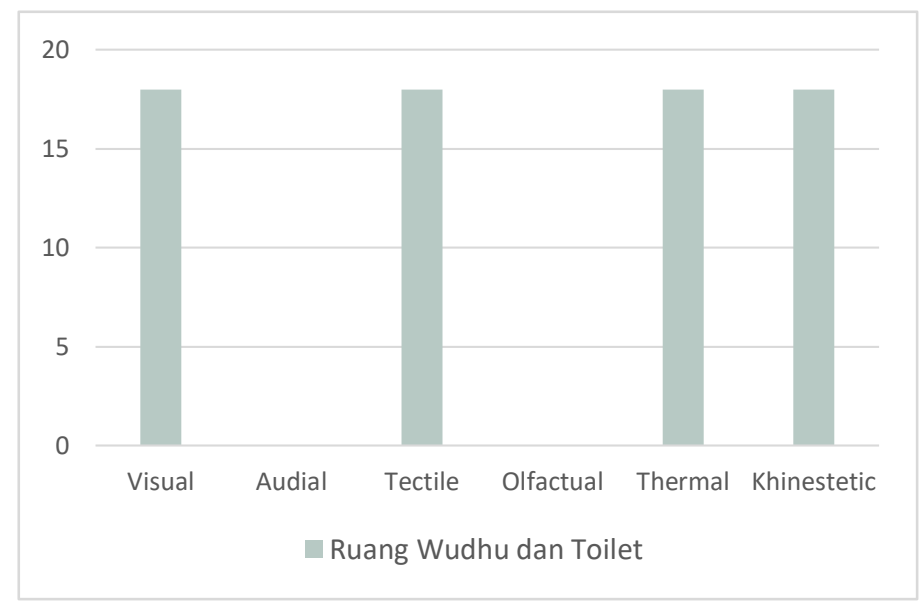

Gambar 5.6 Kesadaran Ruang yang Terlibat Dalam Pembentukan Persepsi Ruang Wudhu dan Toilet

Berdasarkan hasil data kuisioner, elemen ruang yang membentuk persepsi tersebut adalah komposisi, proporsi, dimensi, penghubung, pembatas, lapisan, transparansi, koreografi, cahaya, pembayangan, temperatur, material, tekstur, ornamen, warna dan furnitur. Elemen ruang yang paling mempengaruhi adalah temperatur. Kemudian komposisi, proporsi, dimensi, cahaya, pembayangan, dan furnitur. Kemudian lapisan, koreografi, material, tekstur, ornament, dan warna. Kemudian penghubung, pembatas, dan transparansi. Kemudian yang paling tidak mempengaruhi adalah struktur, suara, dan bau. 


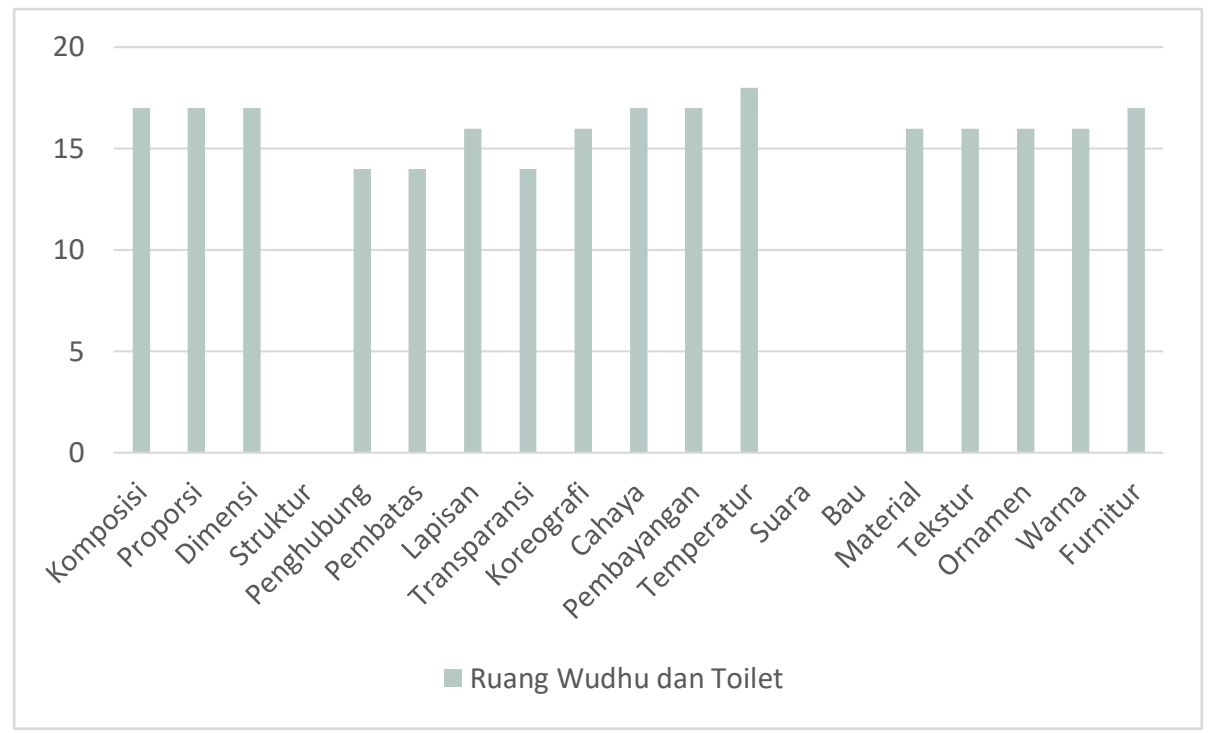

Gambar 5.7 Elemen Ruang yang Membentuk Persepsi Ruang Wudhu dan Toilet

\subsubsection{AREA TANGGA}

Pada ruang wudhu dan toilet, persepsi yang muncul adalah nyaman dan kurang nyaman. Berdasarkan hasil data kuisioner, persepsi tersebut terbentuk dengan melibatkan kesadaran visual, tectile, thermal dan khinestetic, tanpa melibatkan kesadaran audial dan olfactual.

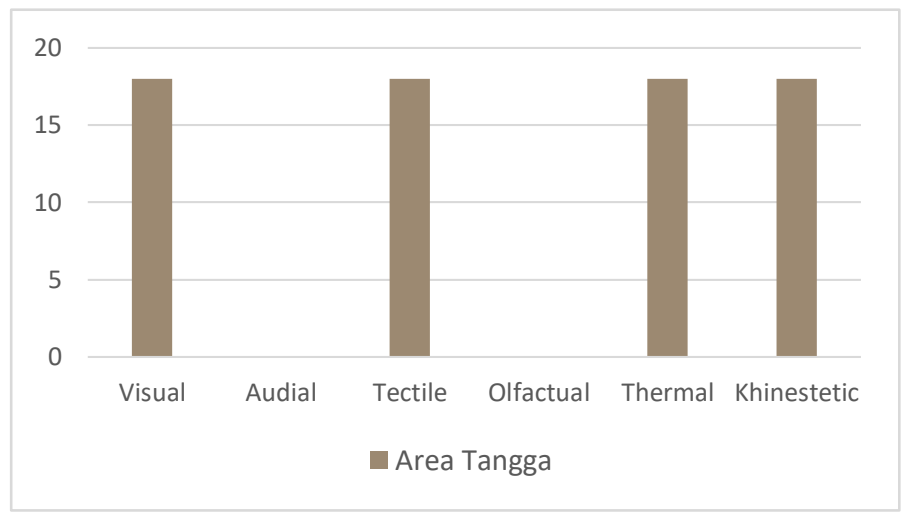

Gambar 5.8 Kesadaran Ruang yang Terlibat Dalam Pembentukan Persepsi Area Tangga

Berdasarkan hasil data kuisioner, elemen ruang yang membentuk persepsi tersebut adalah komposisi, proporsi, dimensi, struktur, penghubung, pembatas, lapisan, transparansi, koreografi, cahaya, pembayangan, temperatur, material, tekstur, ornamen, warna, dan furnitur. Elemen ruang yang paling mempengaruhi adalah penghubung dan pembatas. Kemudian tidak mempengaruhi adalah suara dan bau. 


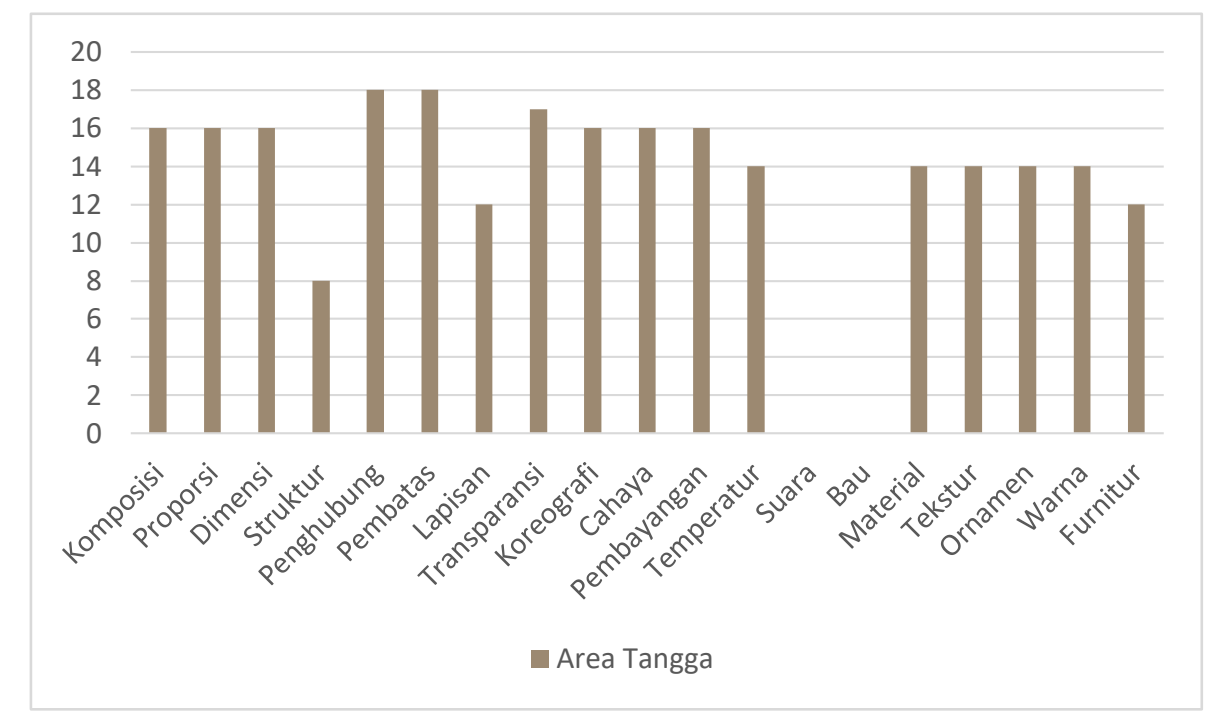

Gambar 5.9 Elemen Ruang yang Membentuk Persepsi Area Tangga

\subsubsection{AREA TRANSISI}

Pada area transisi, persepsi yang muncul adalah kagum dan nyaman. Berdasarkan hasil data kuisioner, persepsi tersebut terbentuk dengan melibatkan kesadaran visual, tectile, thermal. dan khinestetic, tanpa melibatkan kesadaran audial dan olfactual.

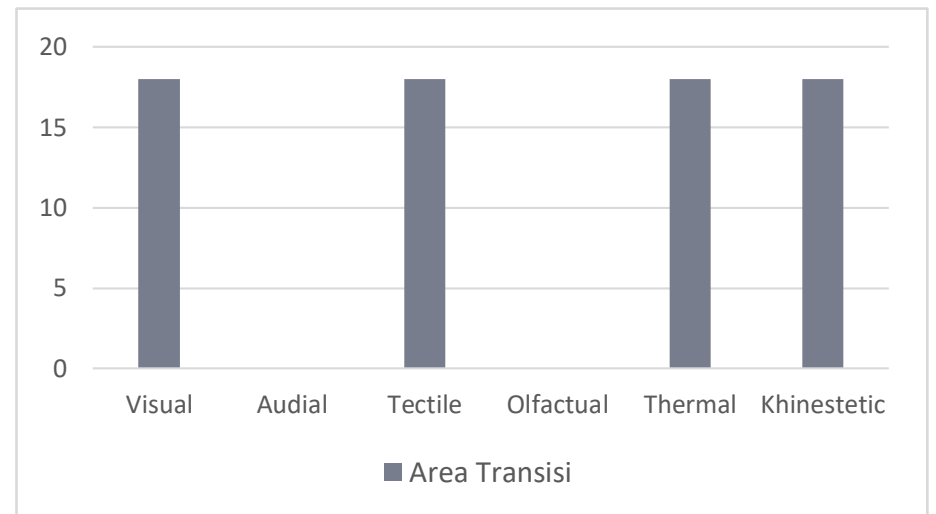

Gambar 5.10 Kesadaran Ruang yang Terlibat dalam Pembentukan Persepsi Area Transisi

Berdasarkan hasil data kuisioner, elemen ruang yang membentuk persepsi tersebut adalah komposisi, proporsi, dimensi, penghubung, pembatas, transparansi, koreografi, cahaya, pembayangan, temperatur, material, tekstur, ornament, dan warna. Elemen yang paling mempengaruhi adalah temperatur, material, tekstur, ornamen dan warna. Kemudian yang tidak mempengaruhi adalah struktur, lapisan, suara, bau, dan furnitur. 


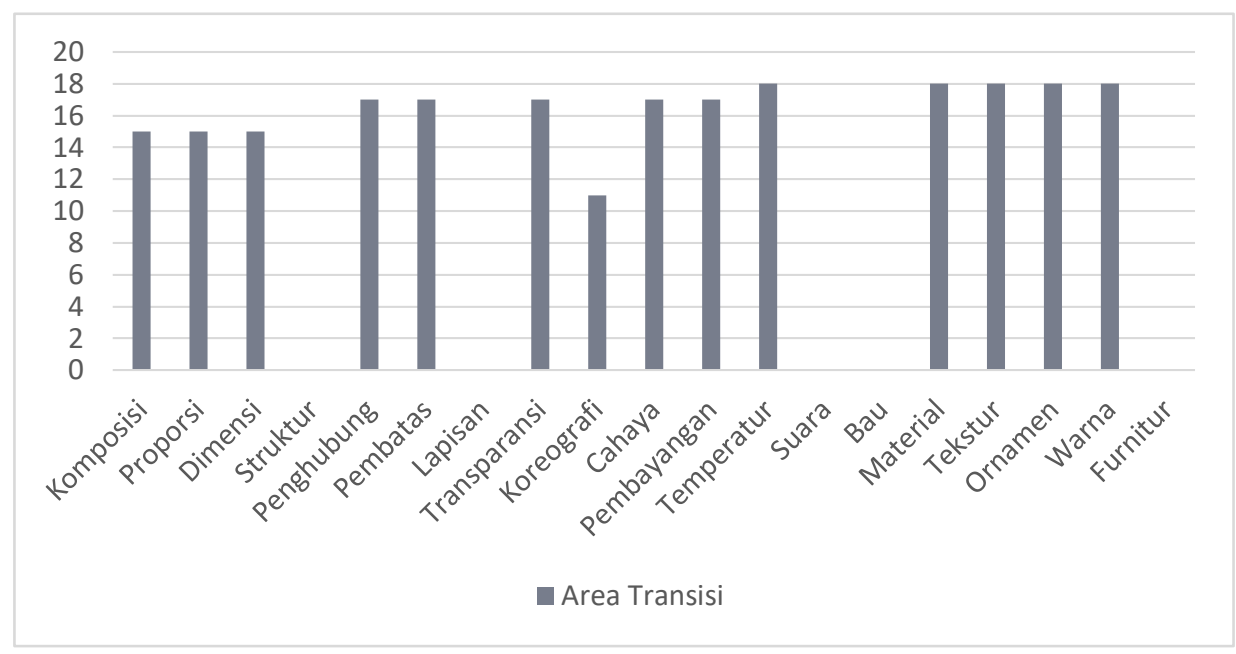

Gambar 5.11 Elemen Ruang yang Membentuk Persepsi Area Transisi

\subsubsection{RUANG SHALAT}

Pada ruang shalat, persepsi yang muncul adalah syahdu, kagum, nyaman, dan terharu. Berdasarkan hasil data kuisioner, persepsi tersebut terbentuk dengan melibatkan kesadaran visual, tectile, thermal dan khinestetic, namun yang paling dominan adalah visual, tanpa melibatkan audial dan olfactual.

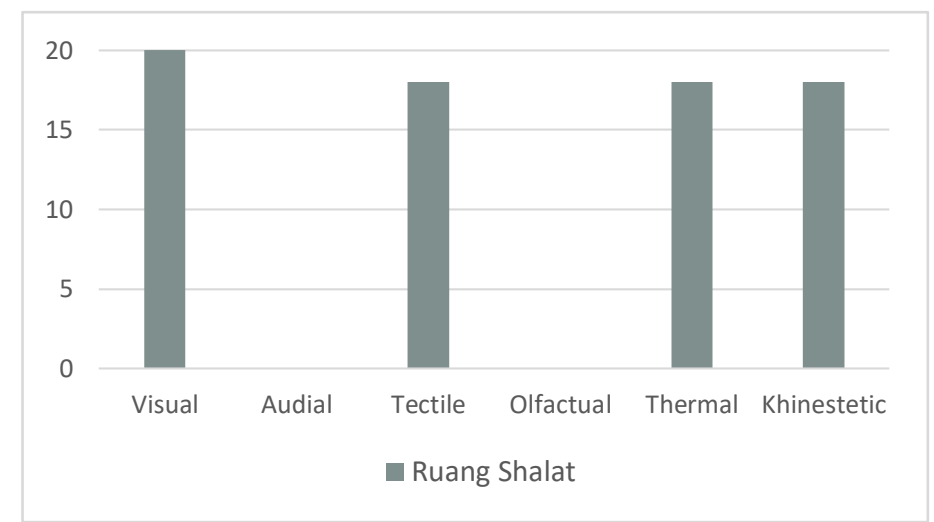

Gambar 5.12 Kesadaran Ruang yang Terlibat Dalam Pembentukan Persepsi Ruang Shalat

Berdasarkan hasil data kuisioner, elemen ruang yang membentuk persepsi tersebut adalah komposisi, proporsi, dimensi, penghubung, pembatas, transparansi, koreografi, cahaya, pembayangan, temperatur, material, tekstur, ornamen dan warna. Elemen ruang yang paling mempengaruhi adalah kompoisi, proporsi, dimensi, struktur, penghubung, pembatas, transparansi, cahaya, dan pembayangan. Kemudian yang paling tidak mempengaruhi adalah lapisan, suara, bau, dan furnitur. 


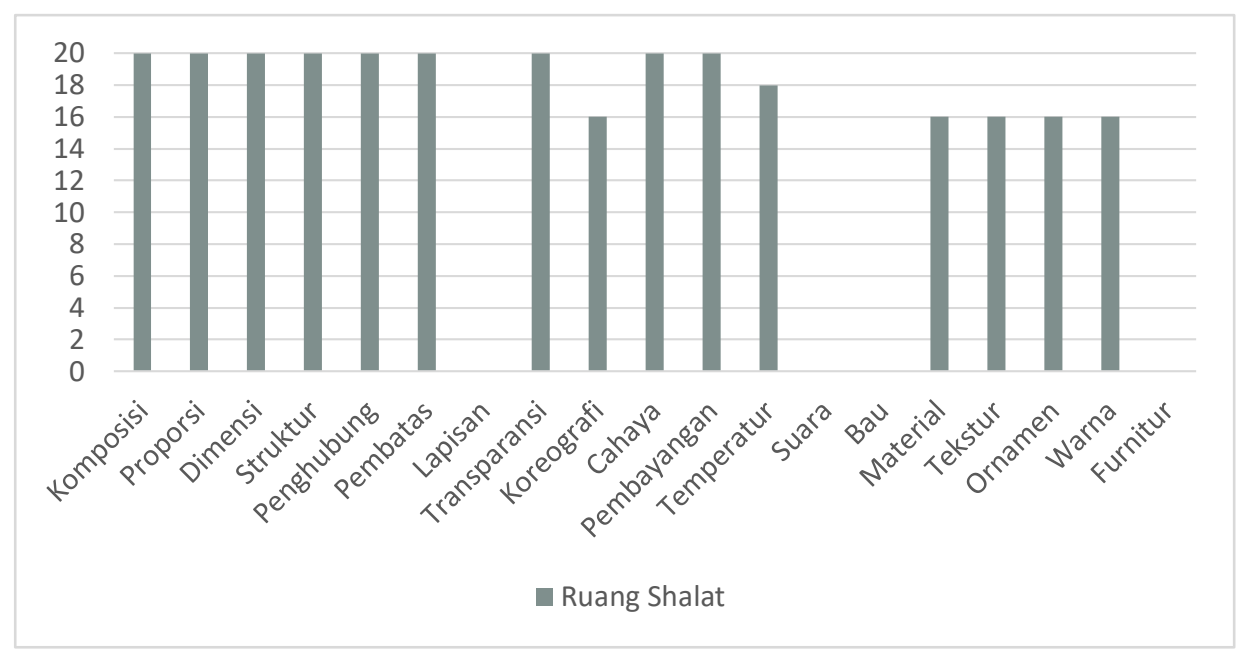

Gambar 5.13 Elemen Ruang yang Membentuk Persepsi Ruang Shalat

\subsection{TEMUAN}

Ruang-ruang yang memiliki karakteristik serupa memiliki persepsi ruang yang kurang lebih juga serupa. Pada area prefunction, ruang wudhu, dan toilet, area tangga serta area transisi, persepsi yang terbentuk adalah kurang lebih nyaman. Terdapat persepsi berbeda yang muncul namun hanya sedikit.

Sedangkan pada area pintu masuk dan ruang shalat yang memiliki karakteristik ruang berbeda juga menghasilkan persepsi yang berbeda. Pada area pintu masuk persepsi yang muncul adalah kagum. Sedangkan pada ruang shalat persepsi yang muncul adalah syahdu, kagum, nyaman, dan terharu.

\section{KESIMPULAN}

\subsection{KESIMPULAN}

Pada bagian ini akan dibahas kesimpulan yang menjawab pertanyaan penelitian. Penelitian ini memiliki dua pertanyaan penelitian, yaitu:

1. Persepsi ruang seperti apa yang dialami pengguna Masjid Jami’e Darussalam?

Persepsi ruang yang terbentuk di Masjid Jami'e Darusslam secara keseluruhan berbeda-beda berdasarkan karakter elemen ruangnya. Ruang dengan karakter yang serupa menghasilkan persepsi yang juga serupa, yaitu area prefunction, ruang wudhu dan toilet, area tangga dan area transisi yang rata-rata menghasilkan persepsi nyaman. Sedangkan ruang-ruang dengan karakter berbeda adalah area pintu masuk yang menghasilkan persepsi kagum, serta ruang shalat yang menghasilkan persepsi syahdu, kagum, nyaman dan terharu. Ruang yang menghasilkan seluruh persepsi yang diperlukan pada masjid menurut Departemen Agama yaitu syahdu, kagum, nyaman dan terharu hanyalah ruang shalat.

2. Elemen ruang seperti apa yang menyebabkan munculnya persepsi ruang pada Masjid Jami'e Darussalam?

Pada area prefunction, ruang wudhu dan toilet, area tangga, serta area transisi secara dominan menghasilkan persepsi nyaman, persepsi lain yang muncul hanya sedikit. Persepsi tersebut dihasilkan dengan melibatkan kesadaran ruang secara visual, tectile, thermal, dan khinestetic. Apabila ditinjau dari elemen-elemen ruangnya, 
komposisi, proporsi, dan dimensi memiliki karakter yang berbeda namun rata-rata memiliki dimensi yang cukup luas. Penghubung, pembatas, cahaya, dan pembayangan juga sedikit berbeda namun rata-rata cukup terang untuk menghasilkan pandangan yang jelas. Elemen-elemen yang paling berpengaruh adalah temperatur, material, tekstur, dan warna. Elemen-elemen tesebut memiliki karakter yang sama yaitu temperatur sejuk, material dinding bata, lantai keramik, plafon gypsum, kaca. dan baja, kemudian tekstur berupa campuran halus dan kasar sesuai kebutuhan, dan warna berupa warna-warna lembut dan formal.

Area pintu masuk menghasilkan persepsi syahdu, kagum dan nyaman melibatkan kesadaran visual, tectile, thermal dan khinestetic. Elemen-elemen pembentuknya adalah komposisi, proporsi, dimensi, struktur, penghubung, pembatas, lapisan, transparansi, koreografi, cahaya, pembayangan, temperatur, material, tekstur, ornamen, warna, dan furnitur. Komposisi berupa bentuk yang kontras antara masjid dengan lingkungan sekitar. Proporsi berupa area pintu masuk yang luas dibandingkan lingkungan sekitar. Dimensi berupa ukuran luas yang merata. Struktur berupa struktur atap ruang shalat yang terlihat dari area pintu masuk. Penghubung dan pembatas berupa bukaan-bukaan yang sangat menghubungkan area pintu masuk dengan ruang di sekitarnya. Lapisan berupa lapisan horizontal pada area pintu masuk dan lapisan vertikal pada masjid yang terlihat dari area pintu masuk, di mana ketinggian masjid kontras dengan ketinggian rata-rata bangunan sekitar. Transparansi berupa tranparansi yang tinggi sehingga aksesibilitas tinggi. Koreografi berupa alur yang jelas menuju area pintu masuk dan alur yang kurang jelas menuju pintu masuk. Cahaya yang banyak sehingga pandangan jelas. Pembayangan yang sedikit sehingga tidak menaungi. Temperatur agak panas karena terbuka dan tidak ternaungi. Material masjid yang modern kontras dengan material bangunan lingkungan sekitar yang kumuh. Tekstur masjid yang terlihat formal kontras dengan tekstur lingkungan sekitar yang terlihat tidak formal. Ornamen pada masjid menimbulkan kesan indah dan syahdu. Warna pada masjid yang terkesan bersih, terang dan suci. Furnitur yang ditata rapi meskipun terdapat kendaraan yang diparkir yang mempersempit sirkulasi menuju pintu masuk. Terdapat elemen-elemen yang menyebabkan ketidaknyamanan namun karena pengguna melewati area pintu masuk hanya sebentar jadi ketidak nyamanan tersebut tidak terlalu berpengaruh.

Pada ruang shalat, persepsi yang dihasilkan adalah syahdu, kagum, nyaman dan terharu. Persepsi tersebut melibatkan kesadaran visual, tectile, thermal dan khinestetic. Elemen-elemen yang mempengaruhi adalah komposisi, proporsi, dimensi, penghubung, pembatas, transparansi, koreografi, cahaya, pembayangan, temperatur, material, tekstur, ornamen dan warna. Komposisi berupa prisma segitiga dan komposisi ruang luar berupa langit, pemukiman dan gedung perkantoran yang kontras yang terlihat dari ruang shalat. Proporsi dan dimensi yang luas. Struktur atap beton yang menjulang dan melancip ke atas, selain itu juga berjajar memanjang membentuk alur ke depan. Penghubung yang terbuka menunjukkan ruang luar. Pembatas yang membagi zona dengan jelas. Transparansi yang tinggi namun aksesibilitas rendah karena berada di lantai atas. Alur memanjang ke depan ke arah pemandangan ruang luar. Cahaya cukup terang dan terdapat cahaya berbentuk garis berjajar yang masuk memperkuat alur yang memanjang ke depan. Pembayangan membentuk kaligrafi dan segitiga pada bagian depan. Temperatur agak panas namun terdapat pendingin sehingga sejuk. Material baja, kaca, dinding bata dan keramik dilapis karpet. Material terkesan bersih dan modern. Tekstur material lembut sehingga terkesan formal. Terdapat ornamen kaligrafi yang indah pada kaca di depan dan dinding di samping. Terdapat juga ornamen bingkai segitiga pada kaca di depan. 
Warna-warna yang terdapat di dalam masjid terkesan lembut, dan terlihat juga warnawarna dari ruang luar yang selaras. Furnitur ditata dengan rapi.

\subsection{SARAN}

Berdasarkan kesimpulan yang didapat, persepsi ruang yang diperlukan oleh sebuah masjid yaitu syahdu, kagum, nyaman dan terharu hanya dapat dirasakan pada ruang shalat. Seharusnya akan lebih baik apabila persepsi tersebut dapat dirasakan pada setiap ruangan di Masjid Jami'e Darussalam. Sehingga pengguna dapat merasakan persepsi tersebut secara keseluruhan ketika berada di dalam Masjid Jami'e Daurssalam, tidak hanya pada ruang shalatnya.

\section{DAFTAR PUSTAKA}

Buku

Altman, I. \& Low, S. (1992). Human Behavior and Environments: Advances in Theory and Research. Volume 12: Place attachment. New York: Plenum Press.

Barker, R.G. (1968). Ecological Psycology: Concept and Methods for Studying the

Environment of Human Behavior. Standford: Standford University Press.

Bert Bielefeld (2013). Basics Architectural Design.

Dharma, Agus. (1998). Teori Arsitektur 3. Jakarta: Universitas Gunadarma

Faqih, Muhammad, (1992). Tipologi Arsitektur Masjid. Surabaya: Penerbit ITS press

Lang J. (1987). Creating Architectural Theory, the Role of the Behavioral Sciences in Environmental Design. Van Nostrand Reinhold Company Inc, New York

Sumalyo, Yulianto. (2000). Arsitektur Mesjid dan Monumen Sejarah Muslim. Yogyakarta: Gadjahmada University Press

Laurens, Joyce Marcella, (2005). Arsitektur dan Perilaku Manusia. Jakarta: PT. Grasindo

Relph, E. (1976) Place and Placelessness. London: Pion Limited

Yi-Fu Tuan, (1997). Space and Place the Perspective of Experience. London: Universitas Minnesota Press

\section{Website}

Tipologi Masjid (2008). Diakses tanggal 13 Desember 2017, dari http://simbi.kemenag.go.id/pustaka/index.php/urusan-agama-islam/kemasjidan/1 kemasjidan

Universitas Pendidikan Indonesia. Persepsi Dalam Arsitektur. Diakses tanggal 13 Desember 2017, dari http://a-research.upi.edu/operator/upload/s_tb_046137_bab_ii.pdf

Persepsi Manusia. Diakses tanggal 13 Desember 2017, dari http://eprints.dinus.ac.id/19103/10/bab2_18450.pdf

Aly Noordien. Teori Persepsi. Diakses tanggal 13 Desember 2017, dari https://www.academia.edu/6123394/Teori_persepsi?auto=download

Universitas Udayana. Persepsi Manusia. Diakses tanggal 13 Desember 2017, dari http://erepo.unud.ac.id/10084/3/2201f1e23c0b5a578380efc2a5224f6b.pdf 